\title{
Endovascular treatment of complex traumatic lesions of the infrapopliteal segment
}

\author{
Tratamento endovascular de lesões traumáticas complexas do segmento \\ infrapopliteo
}

\section{Roberta C. A. Campos, Felipe Nasser, Adnan Neser, José Carlos Ingrund, Marcelo Calil Burihan, Orlando da Costa Barros, Rodrigo Bruno Biagioni, Seleno Glauber de Jesus Silva*}

\begin{abstract}
The occurrence of vascular trauma due to a range of causes has increased considerably. In this setting, endovascular repair has arisen as a new and less invasive approach. We report the case of three patients with lesions of below-knee vessels that were treated by endovascular procedures.
\end{abstract}

Keywords: Angioplasty, vascular trauma, limb.

\section{Introduction}

Many factors can interfere with therapeutic success on the treatment of traumatic lesions in infrapopliteal arteries, such as inaccessibility of the vascular lesion, anatomical distortions due to excessive bleeding, and venous hypertension.

The incidence of popliteal artery lesions corresponds to $5-19 \%$ of all traumatic arterial lesions. These lesions are related to a high rate of limb amputation, mainly when a concomitant distal artery pattern is observed, resulting in a mortality rate of over $5 \%$.

Experience concerning the endovascular treatment of peripheral vascular disease is still very limited and longterm results are yet to be evaluated. However, this modality of treatment has proven to be feasible and safe in special cases.

\section{Case study}

We report the cases of three patients with bulletwounds of below-knee vessels caused by common handgun.

\section{Resumo}

A ocorrência de trauma vascular decorrente de diversas causas aumentou consideravelmente. Nesse contexto, o tratamento endovascular surge como um método novo e menos invasivo. Relatamos o caso de três pacientes com lesões abaixo do joelho que foram tratadas por procedimentos endovasculares.

Palavras-chave: Angioplastia, trauma vascular, membro.

Case 1. A 45-year-old man presented with pain, hematoma and bleeding after right leg penetrating trauma and reduced posterior tibial pulse. Angiography revealed an arteriovenous fistula (Figure 1).

Case 2. A 20-year-old man presented with bleeding after right leg penetrating trauma and normal distal pulses. Angiography revealed an arteriovenous fistula (Figure 2).

Case 3. A 27-year-old man presented with pain and edema 24 hours after left leg penetrating trauma, reduced posterior tibial pulse and fibula fracture. Angiography revealed a pseudoaneurysm of the tibiofibular trunk (Figure 3).

After diagnostic arteriography, wounds were classified as surgically complex and difficult-to-reach lesions. Endovascular treatment was immediately performed using anterograde puncture.

Coronary-coated stents were used because of smalldiameter arteries (3.0- to 3.5-mm-diameter and approximately 20-mm-long Jostent stents).

\footnotetext{
* Hospital Santa Marcelina (HSM), São Paulo, SP, Brazil.

No conflicts of interest declared concerning the publication of this article. Manuscript received May 10 2008, accepted for publication Feb 242009. 

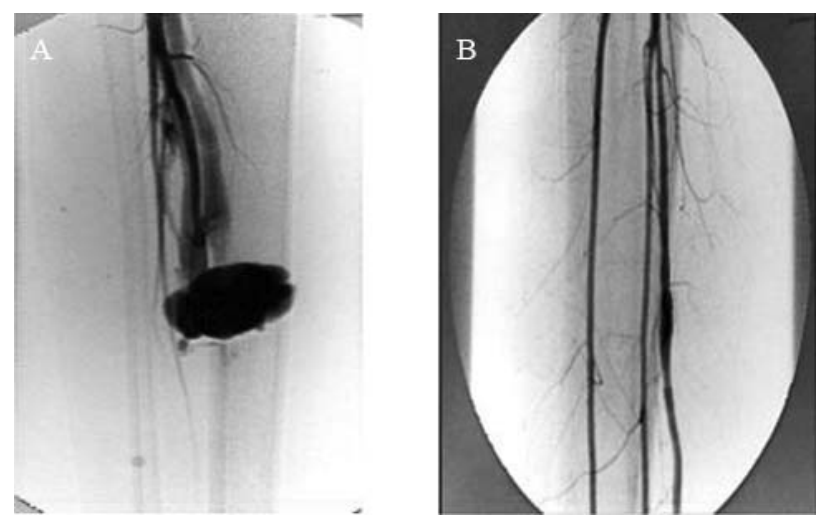

Figura 1 - Case 1: A) diagnostic arteriography; B) angiographic control
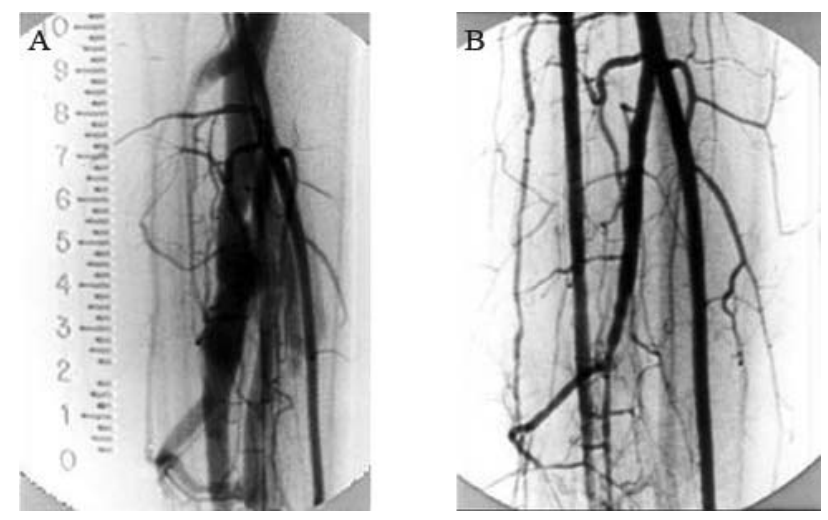

Figura 2 - Case 2: A) diagnostic arteriography; B) angiographic control
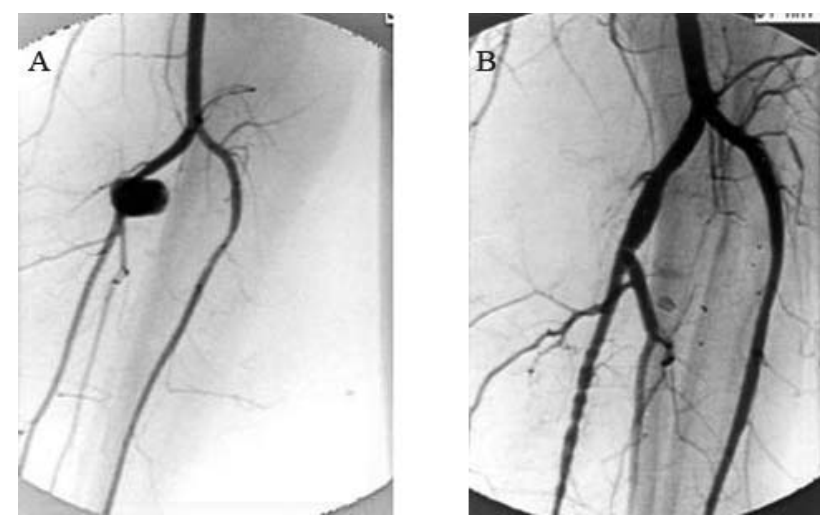

Figura 3 - Case 3: A) diagnostic arteriography; B) angiographic control

Angiographic control confirmed treatment adequacy with complete exclusion of the fistula and the pseudoaneurysm, as shown in Figures 1B (case 1), 2B (case 2) and 3B (case 3). In all patients distal pulses were observed immediately after the end of treatment.

\section{Discussion}

The severity of the ischemia is associated with the extension of the lesion in the affected artery of leg-injured patients. Surgical treatment depends on the patient's general condition and the degree of limb ischemia. Nonconcomitant lesions increase treatment success rates. ${ }^{1,2}$

A successful treatment can be achieved through artery reconstruction, which should be performed up to 6-8 hours after lesion occurrence. Endovascular techniques can be used for vascular control, to assist with surgery, on the sites where proximal and distal control, in relation to the lesion, is difficult to reach. ${ }^{3-5}$

Most endovascular experience with arterial trauma results from the treatment of arterial and arteriovenous fistula pseudoaneurysms. ${ }^{6}$ Potential advantages of endovascular treatment are based on the fact that surgical procedures generally demand longer hospital stay and are associated with higher morbidity rates. ${ }^{7,8}$

Preoperative angiography can accurately estimate the diameter and extension of the injured arterial segments, as well as the nature of the lesion. ${ }^{9}$

Intervention should be performed immediately after diagnosis, reducing complications due to prolonged ischemia time, and in the same room where arteriography was performed. $^{10,11}$

Technological development in stent diameter and composition has increased the success rate of coronary interventions on endovascular treatment of infrapopliteal diseases. The use of coated stents for definitive repair of traumatic lesions has been associated with less anesthetic use, lower blood loss and reduced exposure. ${ }^{11,12}$

In our opinion, endovascular repair resulted in shorter duration of surgery and presented lower risk for these patients.

\section{References}

1. Albrecht RJ, Parra JR. Traumatic peroneal artery pseudoaneurysm: use of preoperative coil embolization. J Vasc Surg. 2004;39:912.

2. Rosa P, O’Donnell SD, Goff JM, Gillespie DL, Starnes B. Endovascular management of a peroneal artery injury due to a military fragment wound. Ann Vasc Surg. 2003;17:678-81.

3. Hunt CA, Kingsley JR. Vascular injuries of the upper extremity. South Med J. 2000;93:466-8.

4. Bose D, Hauptfleisch J, McNally M. Delayed pseudoaneurysm caused by distal locking screw of a femoral intra- 
medullary nail: a case report. J Orthop Trauma. 2006;20:584-6.

5. Medeiros CA, Hatsumura TC, Gusmão DR, Freire LD, Rocha EF, Guillaumon AT. Tratamento endovascular do trauma arterial dos membros. J Vasc Bras. 2008;7:56-61.

6. Inamdar D, Alagappan M, Shyam L, Devadoss S, Devadoss A. Pseudoaneurysm of anterior tibial artery following tibial nailing: a case report. J Orthop Surg (Hong Kong). 2005; 13:186-9.

7. Parodi JC, Schönholz C, Ferreira LM, Bergan J. Endovascular stent-graft treatment of traumatic arterial lesions. Ann Vasc Surg. 1999;13:121-9.

8. Morgan R, Belli AM. Current treatment methods for postcatheterization pseudoaneurysms. J Vasc Interv Radiol. 2003;14:697-710.

9. Rich NM, Baugh JH, Hughes CW. Significance of complications associated with vascular repairs performed in Vietnam. Arch Surg. 1970;100:646-51.
10. Gillespie DL, Woodson J, Kaufman J, Parker J, Greenfield A, Menzoian JO. Role of arteriography for blunt or penetrating injuries in proximity to major vascular structures: an evolution in management. Ann Vasc Surg.1993;7:145-9.

11. Halabi AR, Kandzari DE. The thrill is gone: catheter-based exclusion of a posttraumatic arteriovenous fistula with a covered stent graft. Catheter Cardiovasc Interv. 2005;66:27-33.

12. Ray CE Jr, Johnson J, Cothren CC. Endovascular repair of a large post-traumatic calf pseudoaneurysm and arteriovenous fistula. Mil Med. 2006;171:659-61.

Correspondence:

Roberta C. A. Campos

Rua Santa Marcelina, 177, Itaquera

CEP 08590-070 - São Paulo, SP - Brazil

Tel.: +55 (11) 2070.6000

E-mail: rodcap@ig.com.br 